PNNL-21914

U.S. DEPARTMENT OF ENERGY

Prepared for the U.S. Department of Energy under Contract DE-AC05-76RL01830

\title{
Summer 2012 Testing and Analysis of the Chemical Mixture Methodology - Part I
}
CS Glantz
$X-Y Y u$
RL Coggin
LA Ponder
AE Booth
AJ Petrocchi
SM Horn
J Yao

July 2012

\section{Pacific Northwest}

NATIONAL LABORATORY

Proudly Operated by Battelle Since 1965 


\title{
DISCLAIMER
}

This report was prepared as an account of work sponsored by an agency of the United States Government. Neither the United States Government nor any agency thereof, nor Battelle Memorial Institute, nor any of their employees, makes any warranty, express or implied, or assumes any legal liability or responsibility for the accuracy, completeness, or usefulness of any information, apparatus, product, or process disclosed, or represents that its use would not infringe privately owned rights. Reference herein to any specific commercial product, process, or service by trade name, trademark, manufacturer, or otherwise does not necessarily constitute or imply its endorsement, recommendation, or favoring by the United States Government or any agency thereof, or Battelle Memorial Institute. The views and opinions of authors expressed herein do not necessarily state or reflect those of the United States Government or any agency thereof.

\author{
PACIFIC NORTHWEST NATIONAL LABORATORY \\ operated by \\ BATTELLE \\ for the \\ UNITED STATES DEPARTMENT OF ENERGY \\ under Contract DE-ACO5-76RL01830
}

Printed in the United States of America
Available to DOE and DOE contractors from the
Office of Scientific and Technical Information,
P.O. Box 62, Oak Ridge, TN 37831-0062;
ph: (865) 576-8401
fax: $(865) 5765728$
email: reports@adonis.osti.gov

\author{
Available to the public from the National Technical Information Service, \\ U.S. Department of Commerce, 5285 Port Royal Rd., Springfield, VA 22161 \\ ph: (800) 553-6847 \\ fax: (703) 605-6900 \\ email: orders@nits.fedworld.gov \\ online ordering: http://www.ntis.gov/ordering.htm
}




\title{
Summer 2012 Testing and Analysis of the Chemical Mixture Methodology - Part I
}

\author{
Cliff Glantz \\ Xiao-Ying Yu \\ Rebekah Coggin \\ Lashaundra Ponder \\ Alex Booth \\ Rocky Petrocchi \\ Sarah Horn \\ Juan Yao
}

July 2012

Prepared for the U.S. Department of Energy under Contract DE-AC05-76FL01830

Pacific Northwest National Laboratory

Richland, Washington 99352 


\section{Summary}

This report presents the key findings made by the Chemical Mixture Methodology (CMM) project team during the first stage of their summer 2012 testing and analysis of the CMM. The study focused on answering the following questions:

- What is the percentage of the chemicals in the CMM Rev 27 database associated with each Health Code Number $(\mathrm{HCN})$ ? How does this result influence the relative importance of acute HCNs and chronic HCNs in the CMM data set?

- What is the benefit of using the HCN-based approach? Which Modes of Action and Target Organ Effects ${ }^{\mathrm{a}}$ tend to be important in determining the HCN-based Hazard Index (HI) for a chemical mixture?

- What are some of the potential issues associated with the current HCN-based approach? What are the opportunities for improving the performance and/or technical defensibility of the HCNbased approach? How would those improvements increase the benefit of using the HCN-based approach?

- What is the Target Organ System Effect approach and how can it be used to improve upon the current HCN-based approach? How does the benefits users would derive from using the Target Organ System Approach compare to the benefits available from the current HCN-based approach?

All key research activities were conducted by research interns under the direction and mentorship of PNNL research staff.

\footnotetext{
${ }^{\text {a }}$ The HCN-based approach determines the cumulative HI for a chemical mixture based on the largest cumulative HI value calculated for any Mode of Action and Target Organ Effect category. In other words, only the category that produces the largest cumulative $\mathrm{HI}$ value for a chemical mixture is used in evaluating the hazard posed by that chemical mixture. To help differentiate between the Mode of Action and Target Organ Effect categories in this paper, the Mode of Action is presented using a blue font and the Target Organ Effect is presented using a red font.
} 



\section{Acknowledgments}

The authors would like to thank our colleagues Rocky Petrocchi and Doug Craig for their groundbreaking work in developing and implementing the Chemical Mixture Methodology (CMM) and their suggestions on how to improve the methodology. We would also like to express our appreciation to our colleagues Po-Yung, Lu, Jayne-Anne Bond, John Ciolek, Vern McDougall, and Richard Thomas for their comments and contributions to the CMM program.

The authors are indebted to the DOE Office of Emergency Management and Policy's (NA-41) Jim Fairobent and Dave Freshwater for the support, encouragement, and sponsorship of the CMM.

Finally, the senior members of the research team acknowledge the hard work, dedication, and creativity invested in this project by our research interns. The tireless efforts of Juan Yao, Hua He, Alex Booth, Phil Bouslaugh, and Donna Trott have been invaluable in advancing and updating the CMM. We acknowledge the contributions made by a variety of US Department of Energy and Pacific Northwest National Laboratory science education programs in sponsoring the work by our interns. 



\section{Contents}

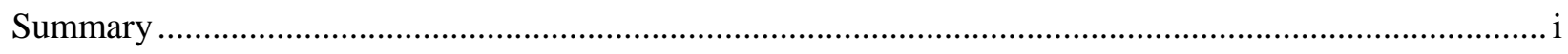

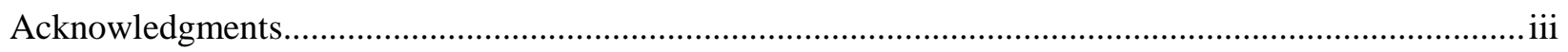

1.0 HCN Values: Percentage of Occurrence in the CMM Data Set ................................................. 1.1

2.0 Testing the HCN-Based Approach and Determining the Relative Contributions of the Modes of

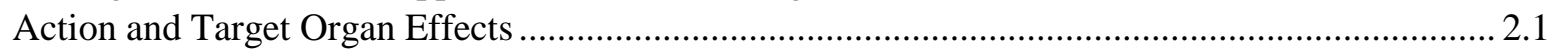

2.1 CMM Rev. 27 Benefits: 74 Test Cases .............................................................................. 2.1

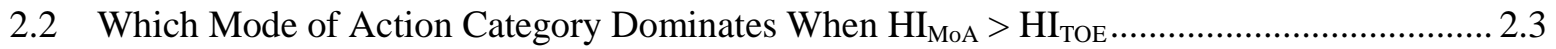

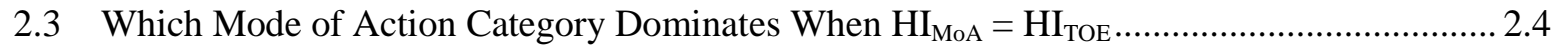

2.4 Which Mode of Action Category Dominates When $\mathrm{HI}_{\mathrm{MoA}}<\mathrm{HI}_{\mathrm{TOE}} \ldots \ldots . . . . . . . . . . . . . . . . . . . . . . . . . . . .2 .4$

2.5 What Happens if the Acute Systemic Toxins Category is Ignored? ....................................... 2.4

3.0 Issues with the Mode of Action and Target Organ Effect Approaches ......................................... 3.1

3.1 Human Health Effects and Biological Systems ............................................................... 3.1

3.2 Issues with the Target Organ Effect Categories .............................................................. 3.1

3.3 Issues with the Mode of Action Categories ........................................................................... 3.2

3.4 Addressing Issues with the Modes of Action and Target Organ Effects ................................ 3.3

4.0 The Comparative Benefits of the HCN-Based Approach in CMM Rev 27 and a Target Organ

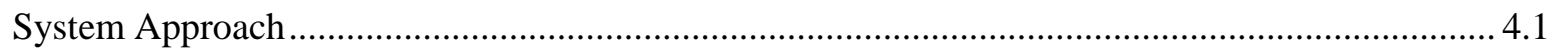

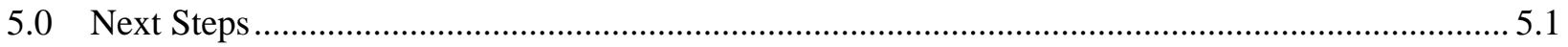

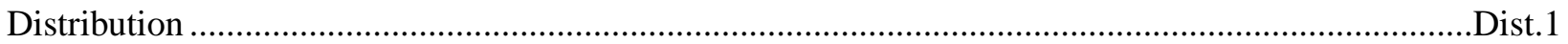




\section{Figures}

Figure 1. Benefit (\%) for CMM Rev 27 HCN-Based Approach: 74 test Cases. ................................. 2.2

Figure 2. Summary Benefit (\%) for CMM Rev 27 HCN-Based Approach: 74 test Cases ...................... 2.2

Figure 3. Summary Comparison of $\mathrm{HI}_{\mathrm{MoA}}$ and $\mathrm{HI}_{\mathrm{TOE}}$ Results for 74 Test Cases.................................. 2.3

Figure 4. Benefit of the Target Organ System Effect - Approach A ..................................................... 4.1

Figure 5. Comparison of the Benefit of the Current CMM Approach with that of the Target Organ

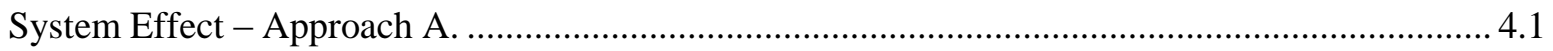

Figure 6. Summary Benefit Comparison of the Current CMM and TOSE-A Approaches ..................... 4.2

\section{Tables}

Table 1. HCN Values and Their Occurrences in CMM Rev 27 Chemicals............................................. 1.3

Table 2. The Target Organ System Effect - Approach A (Rows 1-20) and Three Remaining Mode of

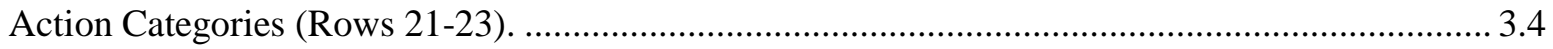




\subsection{HCN Values: Percentage of Occurrence in the CMM Data Set}

Table 1 presents the number and frequency of occurrence of each HCN in CMM Rev 27. The HCNs are listed in order of their frequency of occurrence - from the most common HCNs to the least common. Also provided in this table are the severity rankings of the HCNs for emergency preparedness applications (Petrocchi, 2006) ${ }^{\mathrm{a}}$. These severity rankings are used to assign to each chemical its top-ten HCNs based on severity. A lot of interesting information can be gleaned from this table. Some of the items that caught our attention include:

- The high percentage of chemicals that contain acute HCNs, as opposed to the relatively low percentage of chemical that contain chronic HCNs. The top 16 occurring HCNs in CMM Rev 27 are acute HCNs. The most common acute $\mathrm{HCN}$ is assigned to $60 \%$ of the chemicals in the data set and the $16^{\text {th }}$ most common acute $\mathrm{HCN}$ is assigned to $16 \%$ of the chemicals. In contrast, the most common chronic HCN is only assigned to $14 \%$ of the chemicals. The disparity in the assignment of acute and chronic HCNs is due in part to their relative severity ranking for emergency preparedness. The top 27 of the $60 \mathrm{HCN}$ categories in terms of severity are all acute HCNs. Severity ranking is important because it is used to select the maximum of ten HCNs that can be assigned to each chemical in the CMM data set. Chronic HCNs, with their lower severity rankings, are less likely to make the top ten HCNs for a chemical, resulting in a lower number of occurrences for the chronic HCNs in the CMM data set. The acute HCNs that have lower severity rankings than some of the chronic HCNs are those that have little or no bearing on an individual's ability to take protective actions (i.e., acute reproductive effects) or present low health risks (e.g., mild irritation, odor).

- The high percentage of chemicals that include HCNs that are grouped into in the "Acute Systemic Toxins" category in the Mode of Action. This includes the HCNs that are listed in the following ranking order based on the percentage of chemicals that contain the indicated HCN:

$\begin{array}{llll}\circ & 4^{\text {th }} & (43 \%) \text { Gastrointestinal tract-acute effects } \\ \circ & 8^{\text {th }} & (28 \%) \text { Heart, Cardiovascular system--acute effects } \\ \circ & 9^{\text {th }} & (28 \%) \text { Eye--acute, other than irritation } \\ \circ & 10^{\text {th }} & (28 \%) \text { Brain--acute effects } \\ \circ & 14^{\text {th }} & (22 \%) \text { Kidney-- acute effects } \\ \circ & 15^{\text {th }} & (18 \%) \text { Liver-- acute effects } \\ \circ & 16^{\text {th }} & (16 \%) \text { Hematological effects-acute, unspecified } \\ \circ & 21^{\text {st }} \quad(10 \%) \text { Systemic toxin--acute short-term high hazard effects }\end{array}$

\footnotetext{
${ }^{a}$ Health Code Number (HCN) System Effect-Based Priority Guidelines by Rocky Petrocchi, whitepaper, 2006. These HCN priority guidelines are oriented primarily toward an emergency chemical release event focusing first on those health effects that are immediately or acutely life threatening, then on those that disable or significantly inhibit the ability to perform protective actions or self-rescue, and finally on effects of lesser impact.
} 

$\circ 25^{\text {th }}$
$(7 \%)$
Skin--acute effects other than irritation
$\circ 35^{\text {th }}$
(5\%) Nose--acute effects other than irritation
$\circ \quad 43^{\text {rd }} \quad(<2 \%)$ Bladder--acute effects
$\circ 44^{\text {th }} \quad(<2 \%)$ Bone marrow--acute blood-forming system and other effects
○ $51^{\text {st }} \quad(<1 \%)$ Skin perforation--acute effects other than skin absorption
$\circ 52^{\text {nd }} \quad(<1 \%)$ Bone --acute effects

An analysis of the CMM data set indicates that at an HCN associated with the Acute Systemic Toxins category is assigned to about $\mathbf{8 0 \%}$ of the chemicals in the CMM data. This means that the Acute Systemic Toxins category in the Mode of Action will frequently be involved in determining the cumulative HCN-based HIs for a chemical mixture. Further, the cumulative HIs calculated for the Acute Systemic Toxins category will be, with a high frequency, identical to that produced by simple method of summing the HIs for all the chemicals in the mixture. The implications of this are further examined in the next section of this report.

- The high percentage of chemicals that contain the HCNs for Respiratory Toxins (11.01) and Respiratory Irritants (11.00). These are the two most frequently occurring HCNs in the CMM Rev 27 data set, being assigned to $60 \%$ and $48 \%$ of the chemicals, respectively. These two HCNs contribute to the "Acute Respiratory Toxin" and the "Respiratory System Toxin, Including Severe and Moderate Irritation-Acute" categories. An analysis of the CMM data set indicates that these categories are applicable to $73 \%$ and $83 \%$ of all chemicals, respectively. This indicates that these HCNs' will frequently be the drivers in determining the HCN-based HI based on the Target Organ Effects.

- The high percentage of chemicals that contain the HCNs for Central Nervous System Acute Effects (7.01) and Nervous System Toxins - Acute Effects (7.00). These are the third and $12^{\text {th }}$ most common HCNs and are assigned to $48 \%$ and $27 \%$ of all chemicals, respectively. These two HCNs contribute to the "Nervous System Toxins" and the "Nervous System, Including CNS, Narcosis, and Cholinesterase Toxin" categories. An analysis of the CMM data set indicates that these categories are applicable to $55 \%$ and $67 \%$ of all chemicals, respectively. 
Table 1. HCN Values and Their Occurrences in CMM Rev 27 Chemicals.

\begin{tabular}{|c|c|c|c|c|c|}
\hline $\begin{array}{l}\text { Freq. } \\
\text { Rank }\end{array}$ & $\mathrm{HCN}$ & $\begin{array}{c}\text { \# of Chems } \\
\text { with this } \\
\text { HON }\end{array}$ & $\begin{array}{c}\% \text { of Chems } \\
\text { with this } \\
\text { HCN }\end{array}$ & $\begin{array}{l}\text { Severity } \\
\text { Ranking }\end{array}$ & $\begin{array}{l}\text { Target-Organ Effect (Acute Effects are Unshaded and Chronic Acute HCNs are } \\
\text { Shaded) }\end{array}$ \\
\hline 1 & 11.01 & 2016 & 60 & 10 & Respiratory Irritant -- acute severe or moderate \\
\hline 2 & 11.00 & 1641 & 48 & 19 & Respiratory toxin--acute effects other than irritation \\
\hline 3 & 7.01 & 1617 & 48 & 16 & Central nervous system-acu te effects \\
\hline 4 & 4.07 & 1448 & 43 & 25 & Gastro intestinal tract-acute effects \\
\hline 5 & 15.01 & 1152 & 34 & 7 & Eye irritant--moderate \\
\hline 6 & 15.02 & 1001 & 30 & 12 & Skin irritant-moderate \\
\hline 7 & 8.00 & 970 & 29 & 17 & Narcotic--acute effect \\
\hline 8 & 4.08 & 961 & 28 & 14 & Heart, Cardiovascular system-acute effects \\
\hline 9 & 4.01 & 947 & 28 & 9 & Eye-acute, other than irritation \\
\hline 10 & 4.05 & 940 & 28 & 15 & Brain-acute effects \\
\hline 11 & 14.01 & 928 & 27 & 5 & Eye irritant-severe \\
\hline 12 & 7.00 & 901 & 27 & 18 & Nervous system toxin--acute effects \\
\hline 13 & 14.02 & 805 & 24 & 11 & Skin irritant-severe \\
\hline 14 & 4.09 & 749 & 22 & 21 & Kidney-acute effects \\
\hline 15 & 4.10 & 602 & 18 & 24 & Liver-acute effects \\
\hline 16 & 4.06 & 537 & 16 & 22 & Hematological effects-acu te, u nspecified \\
\hline 17 & 10.00 & 481 & 14 & 38 & Respiratory toxin--chro nic effects \\
\hline 18 & 3.09 & 380 & 11 & 40 & Kidney-ch ronic effects \\
\hline 19 & 3.02 & 372 & 11 & 41 & Hematological effects--chronic, unspecified \\
\hline 20 & 3.10 & 348 & 10 & 43 & Liver-ch ronic effects \\
\hline 21 & 4.00 & 338 & 10 & 13 & Systemic toxin-acute short-term high hazard effects \\
\hline 22 & 3.00 & 335 & 9.9 & 55 & Systemic toxin--chronic effects \\
\hline 23 & 7.11 & 264 & 7.8 & 36 & Central nervous system--chron ic effects \\
\hline 24 & 2.00 & 253 & 7.5 & 32 & Suspect carcinogen or mutagen--chronic effect \\
\hline 25 & 4.11 & 240 & 7.1 & 51 & Skin-acu te effects o ther than irritation \\
\hline 26 & 6.00 & 229 & 6.8 & 4 & Cho linester ase toxin-acute effect \\
\hline 27 & 5.10 & 226 & 6.7 & 50 & Reproductive toxin--chronic effects \\
\hline 28 & 3.08 & 222 & 6.6 & $2 B$ & Heart, Cardiovascular system-ch ronic effects \\
\hline 29 & 3.11 & 211 & 6.2 & 52 & skin--chro nic effects including dermatit is and sensit izat ion \\
\hline 30 & 13.00 & 205 & 6.1 & 3 & Blo od toxin, methemoglobin emia-acute effect \\
\hline 31 & 3.05 & 200 & 5.9 & 35 & Brain--chronic effects \\
\hline 32 & 16.01 & 189 & 5.6 & 56 & Eye irritant--mild \\
\hline 33 & 16.02 & 182 & 5.4 & $5 B$ & Skin irritant-mild \\
\hline 34 & 3.07 & 167 & 4.9 & 44 & Gastro intestinal tract--ch ronic effects \\
\hline 35 & 4.02 & 154 & 4.5 & 20 & Nose--acu te effects other than irritation \\
\hline 36 & 5.00 & 142 & 4.2 & 49 & Reproductive toxin-acute effects \\
\hline 37 & 18.00 & 137 & 4.0 & 2 & Explosive, flammable safety \\
\hline 38 & 7.10 & 119 & 3.5 & 37 & Nervous system toxin--chro nic effects \\
\hline 39 & 17.00 & 101 & 3.0 & 1 & Asp hyxiants, anoxiants-acute effect \\
\hline 40 & 9.00 & 76 & 2.2 & 39 & Respir atory sensit izer--ch ronic effect \\
\hline 41 & 3.06 & 64 & 1.9 & 47 & Eye--ch ronic ocular effects \\
\hline 42 & 3.01 & 58 & 1.7 & 45 & Bladder-ch ronic effects \\
\hline 43 & 4.03 & 55 & 1.6 & 26 & Bladder-acute effects \\
\hline 44 & 4.04 & 53 & 1.6 & 23 & Bone marrow-acute blood-forming system and other effects \\
\hline 45 & 12.00 & 45 & 1.3 & 48 & Blo od toxin, anemia--chronic effect \\
\hline 46 & 3.03 & 42 & 1.2 & 46 & Bone-chronic effects \\
\hline 47 & 19.00 & 32 & 0.9 & 59 & Generally low risk heal th effects -particles, vapors or gases \\
\hline 48 & 1.00 & 30 & 0.9 & 29 & OSHA carcinogen [29 CFR 1910.1000) -chronic effect \\
\hline 49 & 3.04 & 29 & 0.9 & 42 & Bone marrow-chronic blood-forming system and other effects \\
\hline 50 & 2.02 & 26 & 0.8 & 34 & Liver carcinogen--chro nic effect \\
\hline 51 & 4.12 & 24 & 0.7 & 53 & Skin perfor ation-acute effects other than skin absorption \\
\hline 52 & 4.13 & 22 & 0.6 & 27 & Bone-acute effects \\
\hline 53 & 2.01 & $B$ & 0.2 & 33 & Kidn ey carcinogen-chro nic effect \\
\hline 54 & 3.12 & 7 & 0.2 & 54 & Skin perforation-nasal septum perfor at ion and other effects \\
\hline 55 & 1.01 & 6 & 0.2 & 30 & Bladder carcinogen--chronic effect \\
\hline 56 & 14.00 & 6 & 0.2 & 6 & Severe irritant \\
\hline 57 & 1.02 & 3 & 0.09 & 31 & Liver carcinogen-chro nic effect \\
\hline 58 & 15.00 & 3 & 0.09 & 8 & Moderate irritant \\
\hline 59 & 16.00 & 1 & 0.03 & 57 & Mild irritant \\
\hline 60 & 20.00 & 1 & 0.03 & 60 & Generally low risk heal th effects--odor \\
\hline
\end{tabular}




\subsection{Testing the $\mathrm{HCN}$-Based Approach and Determining the Relative Contributions of the Modes of Action and Target Organ Effects}

\subsection{CMM Rev. 27 Benefits: 74 Test Cases}

In this assessment, 74 test cases were studied. These cases were selected to be representative of a range of chemical mixtures and relative concentrations. The 74 test cases consisted of:

1. 24 chemical mixtures that were used in the data set from our team's 2011 analysis. In 12 of these mixtures, the chemicals and their concentrations were based on their inventory in a PNN laboratory. In the other 12 cases, chemicals in the mixtures were randomly selected and each was assigned an identical airborne concentration at the designated receptor. In all 24 cases the chemicals in each mixture are associated with a wide range of HI values.

2. 32 new "ideal" test mixtures, each based on the chemicals found in different PNNL laboratories. The individual chemicals in each of these 32 test cases were assigned concentrations at the designated receptor that would produce an identical $\mathrm{HI}$ for each chemical in the mixture. This "ideal' approach would provide equal weighting to each chemical in the mixture and assure that one chemical did not totally dominate the calculation of the HI for the mixture.

3. 18 new "Real World" test mixtures based on the actual chemicals and the chemical inventories in selected PNNL laboratories. Chemical concentrations at the designated receptor were determined using the EPICode model (http://www.epicode.com).

For each of the test cases, HIs were first computed by simply summing the HIs for all the chemicals in the mixture using data from CMM Rev 27. Next, for each test mixture, the cumulative HI based on the Mode of Action (MoA) and the Target Organ Effect (TOE) were calculated, again using CMM Rev 27 and compared (i.e., $\mathrm{HI}_{\mathrm{MoA}}$ was compared with $\mathrm{HI}_{\mathrm{TOE}}$ ). For each test case, the greatest $\mathrm{HI}$ value from the Modes of Action and Target Organ Effects categories represents the cumulative HCN-based HI for the chemical mixture. Figure 1 presents the "benefit" of using the HCN-based HI over the simple summing of the HIs for all the chemicals in the mixture.

The benefit percentage is equal to: $100 \% *\left(\mathrm{HI}_{\text {Simple Summing }}-\mathrm{HI}_{\mathrm{HCN}}\right.$ Approach $) / \mathrm{HI}_{\text {Simple Summing }}$

where $H I_{H C N}$ Approach is the greater of $H I_{M o A}$ and $H I_{T O E}$.

Figure 2 summaries the benefit results. It shows that the HCN-based approach provided no benefits in $64 \%$ of the test cases, a small benefit $(\leq 5 \%)$ in $12 \%$ of the test cases, benefits of more than $5 \%$ but $\leq 15 \%$ in $15 \%$ of the cases, and benefits of more than $15 \%$ but $\leq 30 \%$ in $9 \%$ of the cases. No tests produced a benefit greater than $30 \%$ benefit.

\footnotetext{
${ }^{a}$ Values were computed using the CMM Wizard after extensive quality assurance testing showed that the CMM Rev 27 Workbook and Wizard were producing identical results. Use of the Wizard substantially speeded up testing and provided other advantages as well (e.g., it is easier to save and post-process Wizard output files).
} 


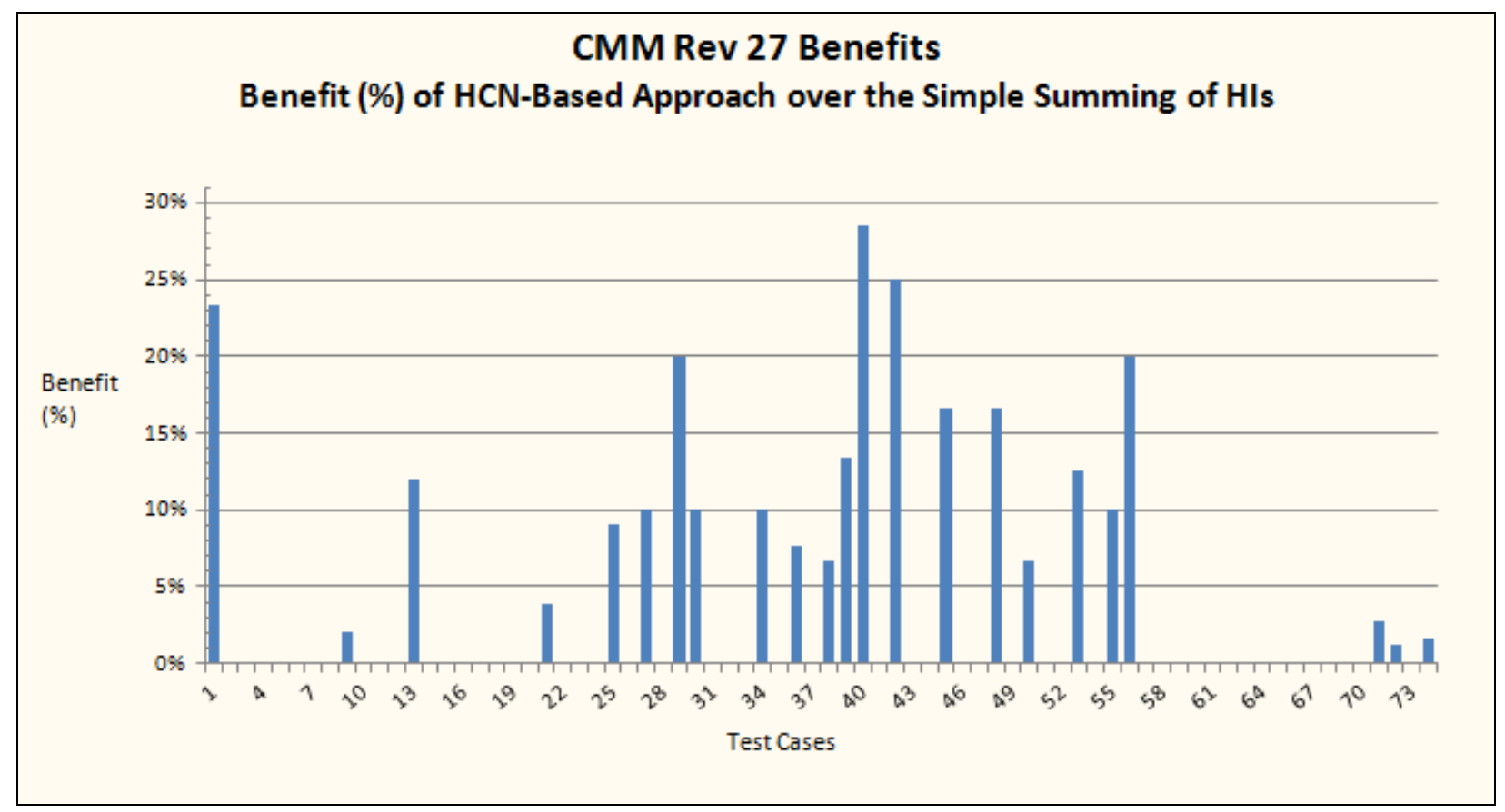

Figure 1. Benefit (\%) for CMM Rev 27 HCN-Based Approach: 74 test Cases. The blue columns represent the benefit percentage for each test case. Test cases in which no benefit occurred are blank.

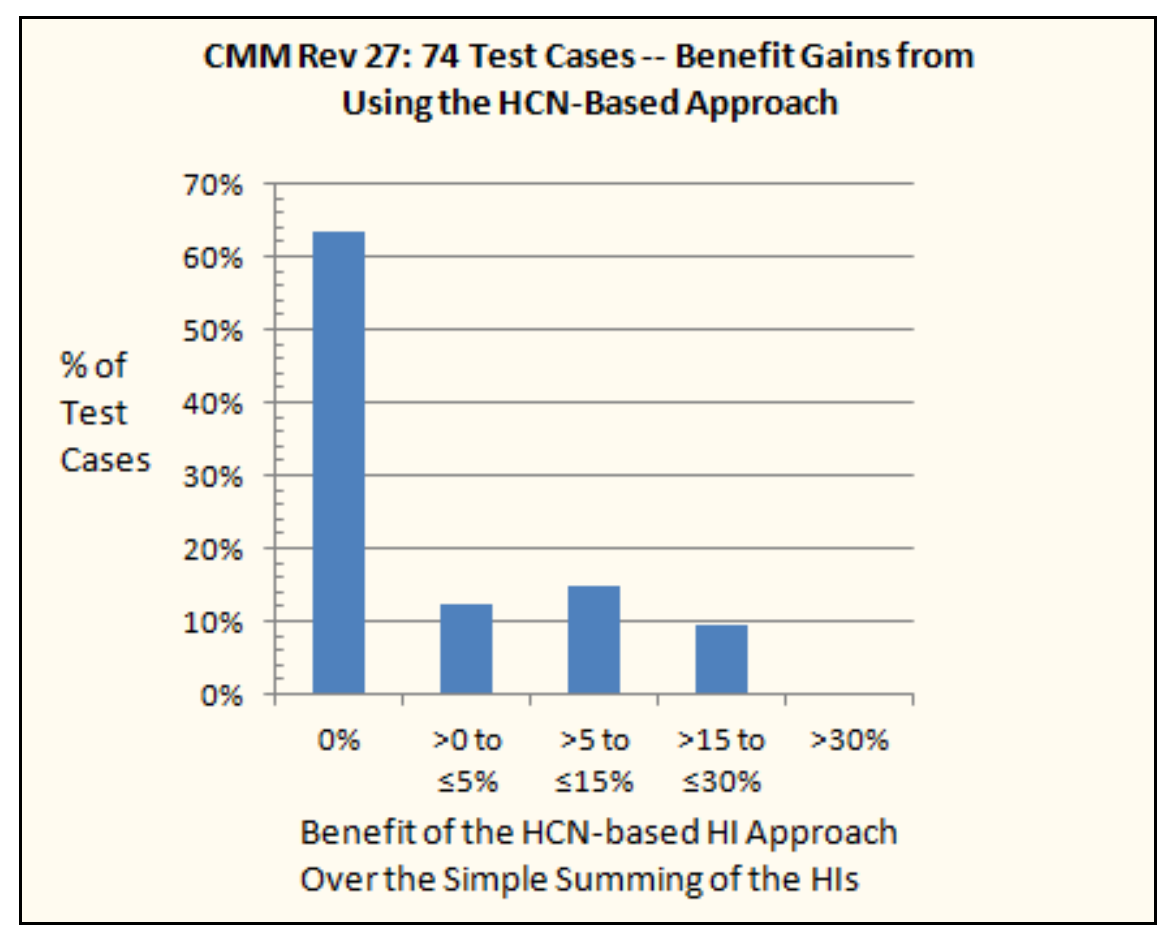

Figure 2. Summary Benefit (\%) for CMM Rev 27 HCN-Based Approach: 74 test Cases 
Digging further, we wanted to see whether the $\mathrm{HCN}$-based $\mathrm{HI}$ and its benefits were based on the $\mathrm{HI}_{\mathrm{MoA}}$ or $\mathrm{HI}_{\mathrm{TOE}}$. The following was found:

- $\mathrm{HI}_{\mathrm{MoA}}=\mathrm{HI}_{\mathrm{TOE}}$ in $53 \%$ of the test cases (39 of the 74 mixtures)

- $\mathrm{HI}_{\mathrm{MoA}}>\mathrm{HI}_{\mathrm{TOE}}$ in $43 \%$ of the test cases (32 of the 74 mixtures).

- $\mathrm{HI}_{\mathrm{TOE}}>\mathrm{HI}_{\mathrm{MoA}}$ in $4 \%$ of the test cases (3 of the 74 mixtures).

These results are presented graphically in Figure 3.

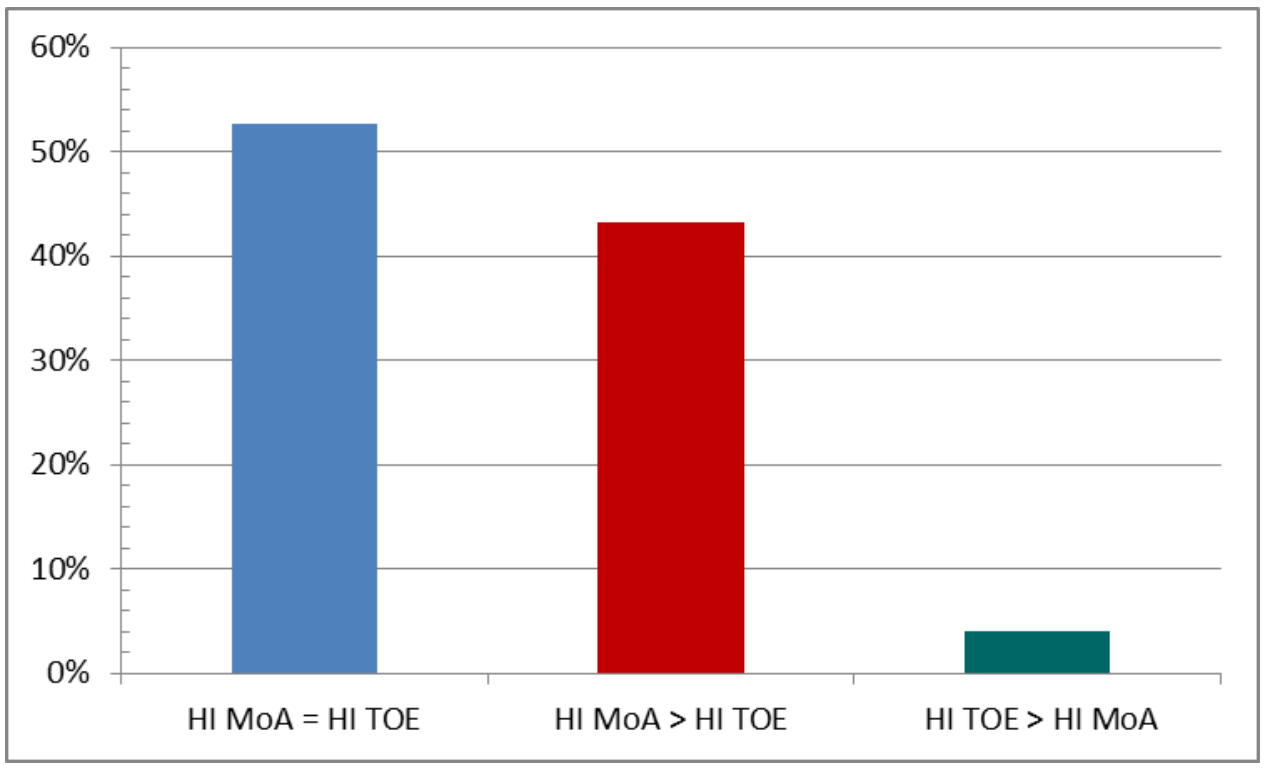

Figure 3. Summary Comparison of $\mathrm{HI}_{\mathrm{MoA}}$ and $\mathrm{HI}_{\mathrm{TOE}}$ Results for 74 Test Cases

\subsection{Which Mode of Action Category Dominates When $\mathrm{HI}_{\mathrm{MoA}}>\mathrm{HI}_{\mathrm{TOE}}$}

For the 32 test cases where $\mathrm{HI}_{\mathrm{MoA}}>\mathrm{HI}_{\mathrm{TOE}}$, the average normalized difference between the $\mathrm{HI}_{\mathrm{MoA}}$ and $\mathrm{HI}_{\mathrm{TOE}}{ }^{\mathrm{a}}$ values was $11 \%$. In 26 of these 32 test cases $(81 \%)$, the Acute Systemic Toxins (HCN=4.xy) were the exclusive driver for the $\mathrm{HI}_{\mathrm{MoA}}$. In another 5 of the 32 test cases $(16 \%)$, the Acute Systemic Toxins were one of the driver's for the $\mathrm{HI}_{\mathrm{MoA}}$ value, though one or more other Mode of Action categories also provided this value. That leaves only one of the 32 test cases (3\%) in which the Acute Systemic Toxins were not involved in determining the $\mathrm{HI}_{\mathrm{MoA}}$. This illustrates the dominant role of the Acute Systemic Toxins category plays in determining the $\mathrm{HI}_{\mathrm{MoA}}$ in the frequent cases in which the $\mathrm{HI}_{\mathrm{MoA}}>$ $\mathrm{HI}_{\mathrm{TOE}}$.

\footnotetext{
${ }^{\text {a }}$ The normalized difference (in percent) for each test case is: $100 \% *\left|\left(\mathrm{HI}_{\mathrm{MoA}}-\mathrm{HI}_{\mathrm{TOE}}\right)\right| / \mathrm{HI}_{\mathrm{MoA}}$.
} 


\subsection{Which Mode of Action Category Dominates When $\mathbf{H I}_{\mathrm{MoA}}=\mathbf{H I}_{\mathrm{TOE}}$}

There are 39 test cases where $\mathrm{HI}_{\mathrm{MoA}}=\mathrm{HI}_{\mathrm{TOE}}$. In 11 out of these 39 test cases $(28 \%)$, the Acute Systemic Toxins category was the exclusive driver for the $\mathrm{HI}_{\mathrm{MoA}}$. In another 20 of the 39 test cases (51\%), the Acute Systemic Toxins were one of the driver's for the $\mathrm{HI}_{\mathrm{MoA}}$ value, though one or more other Mode of Action categories also provided this value. That leaves only 8 of the 39 test cases $(21 \%)$ in which the Acute Systemic Toxins were not involved in determining the $\mathrm{HI}_{\mathrm{MoA}}$.

\subsection{Which Mode of Action Category Dominates When $\mathbf{H I}_{\mathrm{MoA}}<\mathrm{HI}_{\mathrm{TOE}}$}

There are 3 test cases where $\mathrm{HI}_{\mathrm{MoA}}<\mathrm{HI}_{\mathrm{TOE}}$. In one out of these test cases (33\%), the Acute Systemic Toxins category was the exclusive driver for the $\mathrm{HI}_{\mathrm{MoA}}$. In the other two cases, the Acute Systemic Toxins were one of the drivers for the $\mathrm{HI}_{\mathrm{MoA}}$ value and the Acute Respiratory Toxins category also provided the same $\mathrm{HI}_{\mathrm{MoA}}$ value. In each of these three cases the larger $\mathrm{HI}_{\mathrm{TOE}}$ value was determined by the Respiratory system toxin, with irritation (Acute) category.

\subsection{What Happens if the Acute Systemic Toxins Category is Ignored?}

If the Acute Systemic Toxins category is ignored in our 74 test cases, the $\mathrm{HI}_{\mathrm{MoA}}$ decreases by an average of about $10 \%$. The Acute Respiratory Toxins category becomes the dominant $\mathrm{HI}_{\mathrm{MoA}}$ category for $54 \%$ of the test cases and is joined by one or more other categories for another $23 \%$ the test cases. The Nervous System Toxins becomes the dominant category for $18 \%$ of the test cases and is joined by one or more other categories for another $20 \%$ of the test cases. A series of other categories (e.g., Irritants, Acute Reproductive Toxins, Narcotics) play a role in only $12 \%$ of the test cases.

Eliminating the Acute Systemic Toxins category also changes the relative impact of the Mode of Action and Target Organ Effect approaches. Instead of the Mode of Action dominating, the following is seen:

- $\mathrm{HI}_{\mathrm{MoA}}=\mathrm{HI}_{\mathrm{TOE}}$ in $65 \%$ of the test cases (39 of the 74 mixtures)

- $\mathrm{HI}_{\mathrm{MoA}}>\mathrm{HI}_{\mathrm{TOE}}$ in $8 \%$ of the test cases (6 of the 74 mixtures).

- $\mathrm{HI}_{\mathrm{TOE}}>\mathrm{HI}_{\mathrm{MoA}}$ in $27 \%$ of the test cases (20 of the 74 mixtures).

- In summary, the elimination of the Acute Systemic Toxins significantly increases the importance of the Target Organ Effects, reduces the importance of the Modes of Action, and increases the benefit of the HCN-based approach. In Section 3, we will discuss why the elimination of the Acute Systemic Toxins category appears to be justified from a health effects standpoint. 


\subsection{Issues with the Mode of Action and Target Organ Effect Approaches}

\subsection{Human Health Effects and Biological Systems}

The adverse health effects from exposure to chemical mixtures are based on the impacts to biological systems. Using the existing HCN categories, the biological systems on which impacts can be assessed may be grouped the following way:

- Central nervous system

- Peripheral nervous system

- Respiratory system

- Cardiovascular system

- Hematological system (blood)

- Reproductive System

- Vision system

- Integumentary system (skin)

- Urinary System

- Digestive System

- Skeletal system

Other biological systems, like the endocrine and lymphatic system, are not covered by HCNs (owing to the sparseness of toxicity data) and therefore cannot be assessed. However, even if these biological systems were covered by HCNs and there were data to support their assignment to individual chemicals, impacts to these systems would most likely be chronic in nature and therefore not particularly relevant to emergency preparedness applications. As a result, the exclusion of these biological systems from the $\mathrm{CMM}$ is not considered relevant to emergency preparedness. Refinements to the bulleted list of systems are possible (e.g., combining the central and peripheral nervous systems into one system), but the above groupings are adequate for the discussion that follows.

\subsection{Issues with the Target Organ Effect Categories}

The current CMM does not explicitly consider impacts on biological systems, but instead focuses Mode of Action and Target Organ Effects. It should be noted that Target Organ Effects are similar to biological systems, but the current Target Organ Effect categories can be non-conservative for some 
biological systems by failing to consider the aggregate impacts on target organs that need to work together to maintain a biological system. The following are examples in which the current Target Organ Effects categories do not take a system approach:

- Acute eye toxins provide the only impacts on the vision system; acute eye irritation is not considered in evaluating Target Organ Effects even though both eye toxins and eye irritation can have an additive impact on vision and an individual's ability to have sufficient vision acuity to take appropriate protective actions.

- Acute skin toxins and acute skin perforation are considered as separate Target Organ Effects and acute skin irritation is not considered in evaluating Target Organ Effects. Impacts from all three categories would appear to be additive when considering the Integumentary system and the associated cumulative effects that can impair an individual's ability to take appropriate protective actions.

- Acute brain toxins and other acute central nervous system impacts are considered in separate Target Organ Effect categories. Impacts from both categories are additive when considering effects that can impair an individual's ability to have sufficient central nervous system function to take appropriate protective actions.

All of the above appear to represent weaknesses in the HCN-based approach that should be addressed. Although less significant, the following are also potential issues with the current Target Organ Effects categories:

- Acute gastrointestinal tract toxins and acute liver toxins are considered as separate target organ classes. A consideration of gastrointestinal system effects that can impair an individual's ability to take appropriate protective actions should consider as additive impacts from both categories.

- Acute bladder toxins and acute kidney toxins are considered as separate target organ classes. These are different organs but impacts to both organs are additive when considering effects that can impair an individual's urinary function and control.

- Acute hematological system effects and acute bone marrow effects are treated in separate target organ classes, though both have an additive impact on the hematological system.

\subsection{Issues with the Mode of Action Categories}

In a review of the Mode of Action categories, it was unclear how Mode of Action is defined. Clearly it is linked to the HCN categories, but what does this mean from a human health effect standpoint? It does not appear to represent the mechanism by which adverse health effect can occur (a traditional definition of "Mode of Action"), nor does it appear to represent the pathway by which chemicals enter the body. While once useful when the application of HCNs in the CMM was just getting started, many of the Mode of Action legacy categorizations are inconsistent in their scope and are either over-conservative or non-conservative when considering human health effects. Some of the issues uncovered include:

- Combining Acute Systemic Toxins for a lengthy series of unrelated organs (e.g., skin, eye, nose, bladder, bone) into one Mode of Action category does not appear to correlate well with human health effects. Impacts on multiple biological systems do not have the same additive effect as do impacts within 
a single biological system. For example, a chemical mixture that generates separate HI values of 0.3 for acute systemic impacts to the skin, eye, nose, bladder, and bone would produce a cumulative HI value of 1.5 in the Acute Systemic Toxins category even though the PAC threshold is not reached for any single biological system. It seems counterintuitive to equate this example with the potential health effects experienced when a different chemical mixture produces a cumulative HI value of 1.5 just for the Acute Nervous System Toxins category. In the first example, an individual's ability to take timely protective actions should not be substantially degraded. In the latter example, a substantial degradation is quite possible.

- If the Acute Systemic Toxins category is supposed to capture all acute system effects in one category, why does it exclude the most frequently occurring toxin, "Respiratory toxins" (which are assigned to $48 \%$ of all chemicals in the CMM data set) and several other toxins (e.g., reproductive toxins, cholinesterase toxins)? It would seem that for this category to make sense, it would need to include all acute toxins and not just some of them. However, putting all acute systemic toxins is not feasible from a CMM perspective. As it is, the Acute Systemic Toxins category dominates the Mode of Action category; adding more HCNs to this category would ensure that the HCN-based approach would provide seldom provide any benefit over the simple summing of the HIs.

- Combining skin and eye irritation as a Mode of Action category, while placing respiratory irritation in the Respiratory Toxin Mode of Action, does not seem to make sense. If "irritation" is the Mode of Action, why isn't respiratory irritation included in this category? Perhaps "irritation" should be considered based on the target organ system it affects rather than as a separate Mode of Action. If it is maintained, we would need to consider the implications of adding such as common HCN to this category. Would it substantially reduce the benefit of the HCN-based approach by combining impacts to different biological systems (repeating the major drawback currently exhibited by the Acute Systemic Toxins category)?

- In contrast to the combining of multiple organ effects into the Acute System Toxin category, most of the other Mode of Action categories are just subsets of existing Target Organ Effects categories. As such, they do not drive the calculation of the HCN-based HI and may provide less useful information than their associated Target Organ Effects categories. For example, central nervous system impacts are segregated into multiple Mode of Action categories: Acute Systemic Effects (4.05), Cholinesterase Toxins (6.xy), Nervous System Toxins (7.xy), and Narcotics (8.xy).

\subsection{Addressing Issues with the Modes of Action and Target Organ Effects}

The above issues can be addressed a number of different ways. Two options that we are considering are:

1. Maintaining the current Mode of Action and Target Organ Effects approaches, but correct the problematic issues in the individual categories identified in the previous subsections. This may include dropping some categories that are no longer useful or defensible from a human health standpoint and combining some categories that affect the same biological systems. The big downside to this option is that we are still left with uncertainty regarding how to define "Modes of Action" and how to capture biological system effects when organs are examined independently in the current Target Organ Effects categories. 
Table 2. The Target Organ System Effect - Approach A (Rows 1-20) and Three Remaining Mode of Action Categories (Rows 21-23).

\begin{tabular}{|c|c|c|c|c|c|c|c|}
\hline \multirow{2}{*}{$\begin{array}{c}\# \\
1\end{array}$} & \multirow{2}{*}{\begin{tabular}{|l|}
$\begin{array}{l}\text { Target Organ } \\
\text { Systems Effects }\end{array}$ \\
Nervous System (A)
\end{tabular}} & \multicolumn{6}{|c|}{ Includes HCNs Associate with: } \\
\hline & & Brain (4.05) & CNS (7.01) & PNS $(7.00)$ & $\begin{array}{l}\text { cholinesterase } \\
(6.00)\end{array}$ & \begin{tabular}{|l} 
narcotic \\
$(8.00)$
\end{tabular} & \begin{tabular}{|l} 
System toxin- \\
acute $(4.00)$
\end{tabular} \\
\hline 2 & Nervous System (C) & Brain (3.05) & CNS(7.11) & PNS $(7.10)$ & $\begin{array}{l}\text { system toxin- } \\
\text { chronic }(3.00)\end{array}$ & & \\
\hline 3 & Vision System (A) & \begin{tabular}{|l|} 
eye irritant (14.01, \\
$15.01,16.01)$ \\
\end{tabular} & \begin{tabular}{|l}
$\begin{array}{l}\text { eye non-irritant } \\
(4.01)\end{array}$ \\
\end{tabular} & \begin{tabular}{|l|}
$\begin{array}{l}\text { System toxin- } \\
\text { acute }(4.00)\end{array}$ \\
\end{tabular} & \begin{tabular}{|l} 
irritant (14.00, \\
$15.00,16.00)$
\end{tabular} & & \\
\hline 4 & Vision System (C) & ocular effect (3.06) & $\begin{array}{l}\text { system toxin- } \\
\text { chronic (3.00) }\end{array}$ & & & & \\
\hline 5 & $\begin{array}{l}\text { Integumentary System } \\
\text { (A) }\end{array}$ & $\begin{array}{l}\text { skin irritant (14.02, } \\
15.02,16.02)\end{array}$ & $\begin{array}{l}\text { skin non-irritant } \\
\text { (4.11) }\end{array}$ & skin perf. (4.12) & $\begin{array}{l}\text { System toxin- } \\
\text { acute }(4.00)\end{array}$ & \begin{tabular}{|l|} 
irritant \\
$(14.00,15.00$, \\
$16.00)$ \\
\end{tabular} & \\
\hline 6 & $\begin{array}{l}\text { Integumentary System } \\
\text { (C) }\end{array}$ & $\begin{array}{l}\text { skin sensitizer } \\
(3.11)\end{array}$ & $\begin{array}{l}\text { skin perforation } \\
\text { (3.12) }\end{array}$ & $\begin{array}{l}\text { system toxin- } \\
\text { chronic }(3.00)\end{array}$ & & & \\
\hline 7 & Urinary System (A) & kidney (4.09) & bladder (4.03) & $\begin{array}{l}\text { System toxin- } \\
\text { acute }(4.00)\end{array}$ & & & \\
\hline 8 & Urinary System (C) & kidney (3.09) & bladder (3.01) & \begin{tabular}{|l} 
kidney \\
carcinogen \\
$(2.01)$
\end{tabular} & \begin{tabular}{|l} 
bladder \\
carcinogen \\
$(1.01)$
\end{tabular} & $\begin{array}{l}\text { system toxin- } \\
\text { chronic }(3.00)\end{array}$ & \\
\hline 9 & Digestive System (A) & \begin{tabular}{|l|} 
gastrointestinal \\
tract $(4.07)$ \\
\end{tabular} & liver $(4.10)$ & $\begin{array}{l}\text { System toxin- } \\
\text { acute }(4.00)\end{array}$ & & & \\
\hline 10 & Digestive System[C] & \begin{tabular}{|l} 
gastrointestinal \\
tract $(3.07)$
\end{tabular} & liver $(3.10)$ & $\begin{array}{l}\text { liver carcinogen } \\
(1.02,2.02)\end{array}$ & $\begin{array}{l}\text { system toxin- } \\
\text { chronic }(3.00)\end{array}$ & & \\
\hline 11 & $\begin{array}{l}\text { Cardiovascular System } \\
\text { (A) }\end{array}$ & heart (4.08) & $\begin{array}{l}\text { System toxin- } \\
\text { acute }(4.00)\end{array}$ & & & & \\
\hline 12 & $\begin{array}{l}\text { Cardiovascular System } \\
\text { (C) }\end{array}$ & heart (3.08) & $\begin{array}{l}\text { system toxin- } \\
\text { chronic }(3.00)\end{array}$ & & & & \\
\hline 13 & Respiratory System (A) & \begin{tabular}{|l} 
respiratory irritant \\
$(11.01)$
\end{tabular} & $\begin{array}{l}\text { respiratory non- } \\
\text { irritant(11.00) }\end{array}$ & $\begin{array}{l}\text { nose non } \\
\text { irritant(4.02) }\end{array}$ & $\begin{array}{l}\text { System toxin- } \\
\text { acute }(4.00)\end{array}$ & & \\
\hline 14 & Respiratory System (C) & $\begin{array}{l}\text { respiratory toxin } \\
(10.00)\end{array}$ & $\begin{array}{l}\text { respiratory } \\
\text { sensitizer }(9.00)\end{array}$ & \begin{tabular}{|l|} 
nasal septum \\
perforation \\
(3.12)
\end{tabular} & $\begin{array}{l}\text { nuisance } \\
(19.00)\end{array}$ & $\begin{array}{l}\text { system toxin- } \\
\text { chronic }(3.00)\end{array}$ & $\begin{array}{l}\text { generally low } \\
\text { risk-odor } \\
(20.00)\end{array}$ \\
\hline 15 & $\begin{array}{l}\text { Hematological } \\
\text { System }(A)\end{array}$ & $\begin{array}{l}\text { methemoglob- } \\
\text { inemia }(13.00)\end{array}$ & $\begin{array}{l}\text { hematological } \\
\text { effects }(4.06)\end{array}$ & $\begin{array}{l}\text { bone marrow } \\
(4.04)\end{array}$ & liver $(4.10)$ & $\begin{array}{l}\text { System toxin- } \\
\text { acute }(4.00)\end{array}$ & \\
\hline 16 & $\begin{array}{l}\text { Hematological } \\
\text { System(C) }\end{array}$ & $\begin{array}{l}\text { hematological } \\
\text { effects (3.02) }\end{array}$ & anemia $(12.00)$ & $\begin{array}{l}\text { bone marrow } \\
(3.04)\end{array}$ & liver $(3.10)$ & $\begin{array}{l}\text { system toxin- } \\
\text { chronic }(3.00)\end{array}$ & $\begin{array}{l}\text { liver } \\
\text { carcinogen } \\
(1.02,2.02)\end{array}$ \\
\hline 17 & Reproductive System(A) & $\begin{array}{l}\text { Reproductive } \\
\text { effect }(5.00)\end{array}$ & $\begin{array}{l}\text { System toxin- } \\
\text { acute }(4.00)\end{array}$ & & & & \\
\hline 18 & Reproductive System(C) & $\begin{array}{l}\text { Reproductive } \\
\text { effect }(5.10)\end{array}$ & $\begin{array}{l}\text { system toxin- } \\
\text { chronic }(3.00)\end{array}$ & & & & \\
\hline 19 & Skeletal System (A) & bone (4.13) & $\begin{array}{l}\text { System toxin- } \\
\text { acute }(4.00)\end{array}$ & & & & \\
\hline 20 & Skeletal System (C) & bone (3.03) & $\begin{array}{l}\text { system toxin- } \\
\text { chronic }(3.00)\end{array}$ & & & & \\
\hline 21 & Asphyxiants(A) & $\begin{array}{l}\text { Asphyxiants, } \\
\text { anoxiants }(17.00)\end{array}$ & & & & & \\
\hline 22 & Explosion & \begin{tabular}{|l|} 
Explosive, \\
flammable safety \\
$(18.00)$ \\
\end{tabular} & & & & & \\
\hline 23 & Carcinogen & $\begin{array}{l}\text { OSHA carcinogen } \\
(1.00)\end{array}$ & $\begin{array}{l}\text { suspect } \\
\text { carcinogen or }\end{array}$ & \begin{tabular}{|l} 
kidney \\
carcinogen
\end{tabular} & \begin{tabular}{|l} 
bladder \\
carcinogen
\end{tabular} & $\begin{array}{l}\text { liver } \\
\text { carcinogen }\end{array}$ & \\
\hline
\end{tabular}


2. Adopting a new Target Organ System Effect categorization scheme. This would focus on biological systems. HCNs that affect the same biological systems would be combined together into target organ system categories. The Target Organ Effects categories would be maintained after undergoing some minor modifications (to address the issues identified in a prior subsection) and would primarily be used to provide organ specific information to users (i.e., it would seldom, if ever, by itself provide the $\mathrm{HCN}$-based HI for the chemical mixture). We would suggest renaming this category to "Specific Target Organ Effects" (STOE) to clearly differentiate it from the Target Organ System Effect approach. Finally, the number of Mode of Action categories would be substantially reduced to eliminate those categories which are no longer useful or defensible from a human health standpoint, or are redundant because comparable information is provided by the Target Organ System Effects or Specific Target Organ Effects categories.

Several slightly different approaches for the new Target Organ System Effect categories are being considered and evaluated. Table 2 provides Target Organ System Effect - Approach A ("TOSE-A") and also includes three remaining Mode of Action categories. This Target Organ System Effect approach consists of 10 organ systems and it separately evaluates the acute and chronic effects to each of these organ systems (in the same manner as the current Modes of Action and Target Organ Effects approaches).

This option should produce more technically defensible categories than the first option, is easier to explain, and it provides more detailed health effects information to the user. Its drawback is that it represents a greater departure from the current approach than Option 1 and would require more extensive revisions to the CMM workbook. Both options can be readily accommodated by the more flexible CMM Wizard. 


\subsection{The Comparative Benefits of the HCN-Based Approach in CMM Rev 27 and a Target Organ System Approach}

Figure 4 shows the benefit from using the Target Organ System Effect - Approach A when compared to the simple sum of the HIs. Results are shown for 74 representative test cases. Figure 5 combines the results presented in Figure 1 (the benefit of the current CMM Rev 27 approach) with the results presented in Figure 5. This illustrates the difference in benefit achieved with the current CMM approach and the proposed Target Organ System Effect approach.

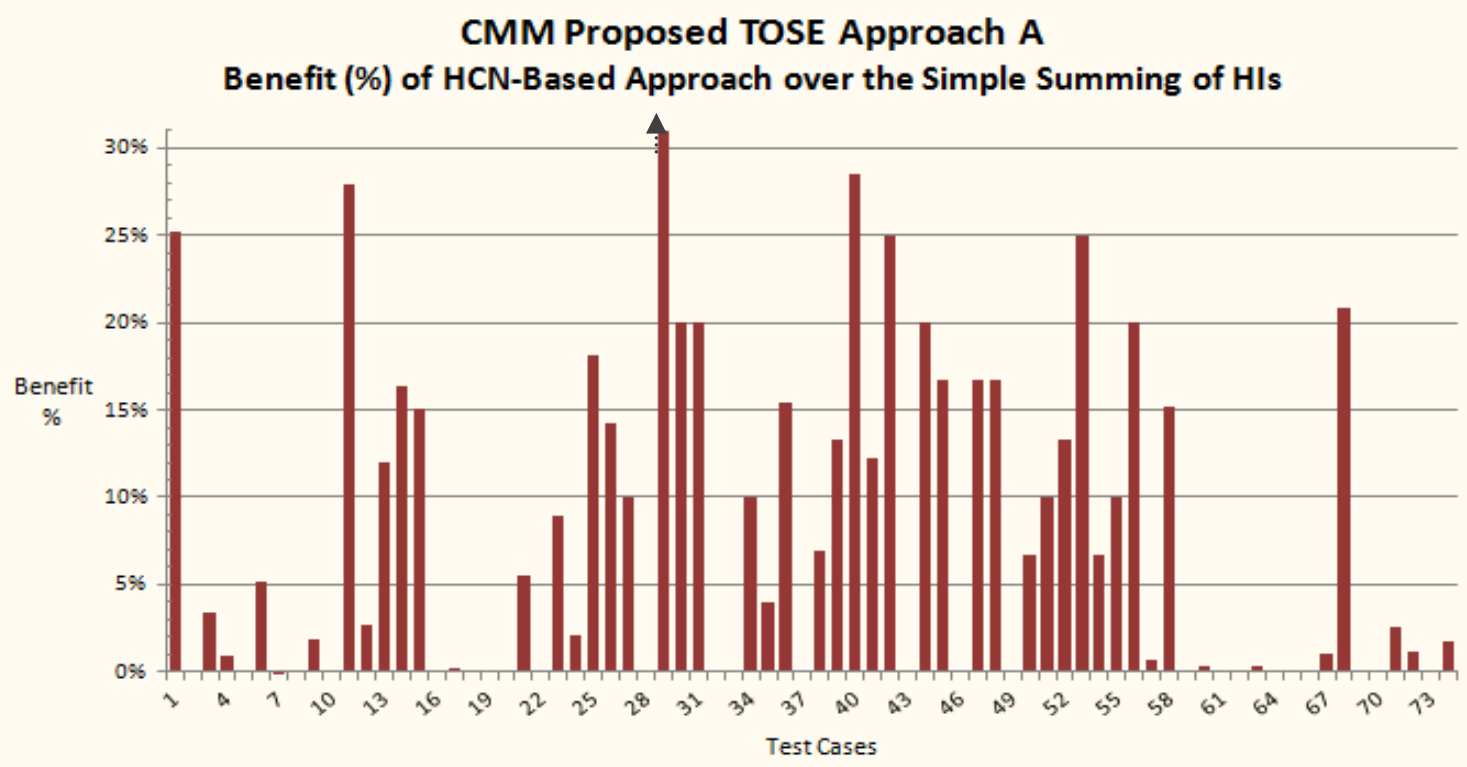

Figure 4. Benefit of the Target Organ System Effect - Approach A over the Simple Summing of the HIs

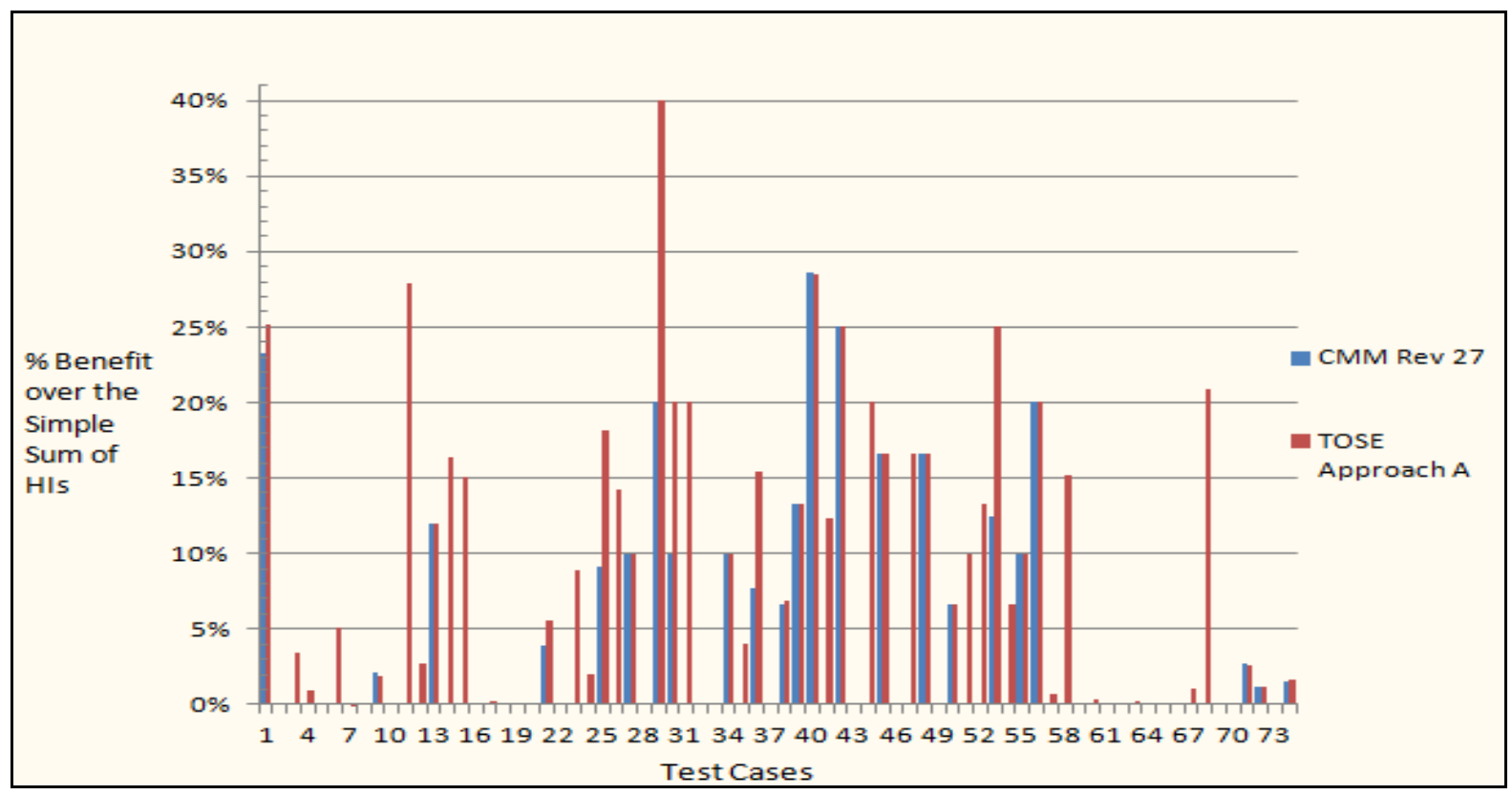

Figure 5. Comparison of the Benefit of the Current CMM Approach with that of the Target Organ System Effect - Approach A. 
The Target Organ System Effect has a lot more cases with a measurable benefit and a much higher percentage of large benefits when compared to the CMM Rev 27 approach. Interestingly, in not one test case does the current HCN-based approach provide a greater benefit than the Target Organ System Effect approach. In other words, the benefit associated with using the Target Organ System Effect approach is either the same or greater than that of the current $\mathrm{HCN}$-based approach.

Figure 6 presents this benefit comparison in summary form. It shows that for the 74 test case, the current CMM approach has twice the number of test cases as the Target Organ System Effect approach in which no benefit was provided over the simple summing of the HIs. The Target Organ System Effect approach has about three times as many test cases as the current CMM approach in which the benefit over the simple summing of the HIs was $15 \%$ or more.

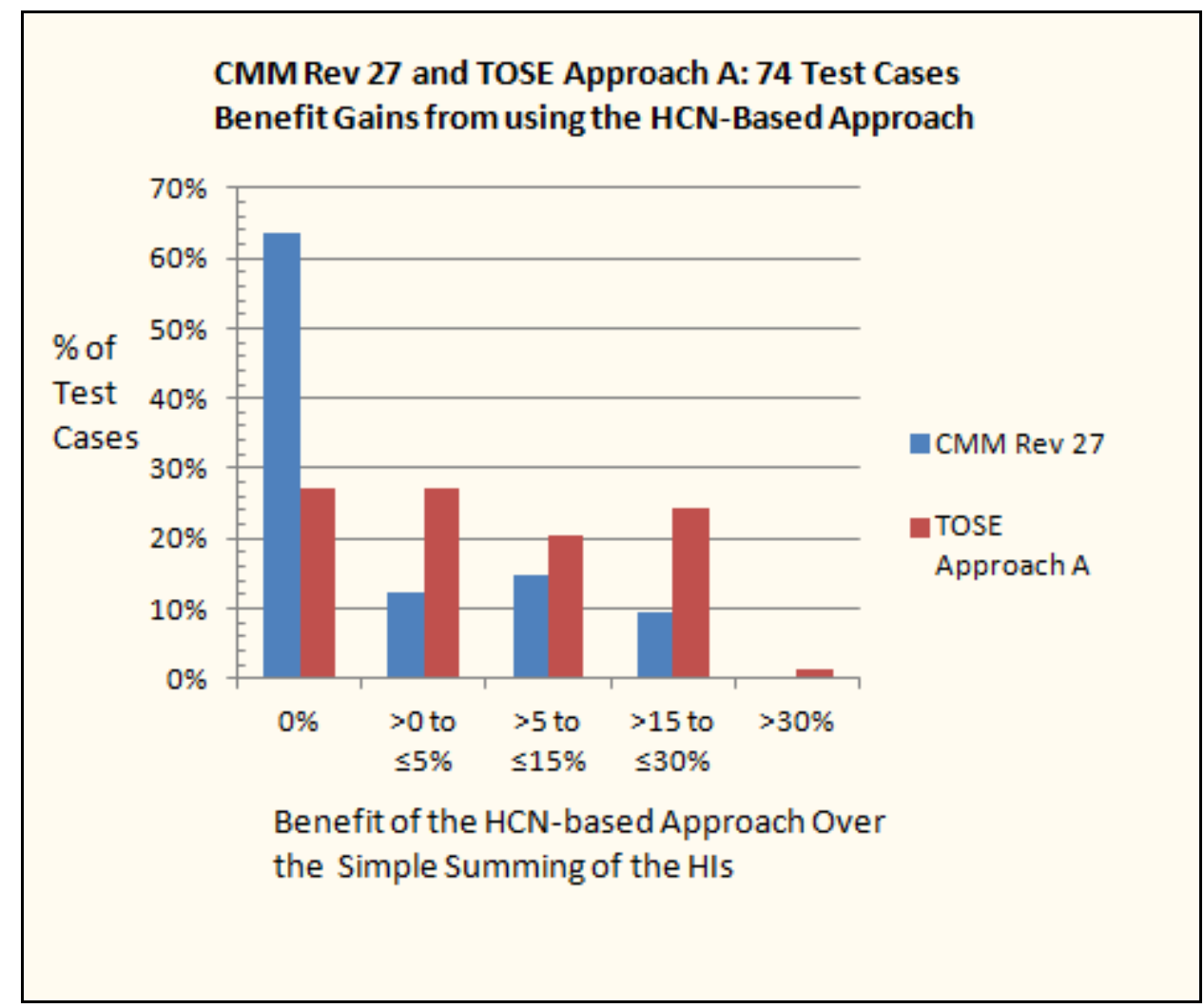

Figure 6. Summary Benefit Comparison of the Current CMM and TOSE-A Approaches 


\subsection{Next Steps}

The CMM team welcomes reviewer comments and suggestions. The interns will have additional test data to report shortly (i.e., in early August). One of several major elements in their additional testings involves the expansion in the number of test cases from 74 to close to 400 . The ability to test large number of chemical mixtures in quick and efficient manner is faciliated by the CMM Wizard and a new intern-developed testing tool, based on the CMM Wizard, which we have nicknamed the "CMM Alchemist" 
PNNL-21914

\section{Distribution}

No. of

Copies

ONSITE

6 Pacific Northwest National Laboratory

Cliff Glantz (2) K9-30

Xiao-Ying Yu (2) K9-30

Juan Yao K9-30

Eva Hickey K3-66

Dist. 1 


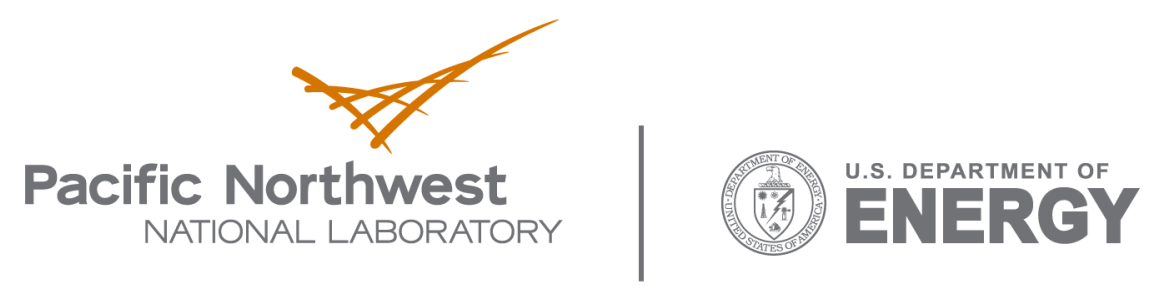

902 Battelle Boulevard

P.O. Box 999

Richland, WA 99352

1-888-375-PNNL (7665)

www.pnl.gov 